\title{
Penerapan K-Means Clustering Untuk Penentuan Klasterisasi Beasiswa Bidikmisi Mahasiswa
}

\author{
Agustin Ely Rahayu, ${ }^{1, *}$, Khoiril Hikmah ${ }^{2}$, Nanik Yustia Ningsih ${ }^{3}$, Abd. Charis Fauzan ${ }^{4}$ \\ Program Studi Ilmu Komputer, Universitas Nahdlatul Ulama Blitar, Indonesia \\ ${ }^{1}$ agustinely25@gmail.com; ${ }^{2}$ avp.khoir@gmail.com; ${ }^{3}$ nanikyustia1999@gmail.com; ${ }^{4}$ abdcharis@ unublitar.ac.id \\ * corresponding author
}

\section{ARTIKEL INFO}

Article history

Diterima: 27 Oktober 2019

Direvisi: 15 November 2019

Diterbitkan: 30 Desember 2019

\begin{abstract}
ABSTRAK
Penelitian ini bertujuan untuk membantu menentukan centroid calon beasiswa sehingga dapat memberikan pengusulan dalam kelompok sangat layak, layak, dipertimbangkan, dan kurang layak untuk menerima beasiswa bidikmisi dengan 6 syarat. Penelitian ini menggunakan sebanyak 25 data sintetis menggunakan algoritma K-Means yang mampu membantu mengklarifikasi mahasiswa, untuk dipertimbangkan atu tidak layak untuk menerima beasiswa bidikmisi. Jadi, dengan adanya penelitian ini, membatu mengelompokkan penyaluran bidikmisi kepada mahasiswa dengan syarat seperti penghasilan orang tua, keadaan rumah, jumlah tanggungan orang tua, dan prestasi mahasiswa dalam bidang akademik.
\end{abstract}

\section{PENDAHULUAN}

Beasiswa bidikmisi adalah bantuan dari pemerintah diperuntukan mahasiswa yang berasal dari kelangan yang kurang mampu agar tetap bisa melanjutkan ke perguruan tinggi. Beasiswa ini disalurkan melalui perguruan tinggi di bawah Kementerian Pendidikan dan Budaya (Mendikbud). Seleksi pendaftar beasiswa bidikmisi dilakukan saat proses penerimaan mahasiswa baru oleh perguruan tinggi yang ditunjuk oleh Mendikbud. Penyaluran beasiswa bidikmisi pada mahasiswa baru ini juga harus memperhatikan syaratsyarat tertentu sebelum di berikan kepada mahasiswa yang bersangkutan [1]. Syarat yang harus dipenuhi seperti penghasilan orang tua, kondisi rumah, jumlah tanggungan orang tua, dan prestasi mahasiswa di bidang akademik. Mahasiswa lama bisa mengikuti pendaftaran beasiswa bidikmisi dengan syarat yang ada dengan tambahan IPK yang minimal 3.00. Algoritma K-Means adalah salah satu cara untuk meclustering data dan membagi data yang ada untuk membentuk cluster. Algoritma ini membagi data ke dalam cluster sehingga data yang memiliki karakter yang sama diclusterkan ke dalam satu cluster yang sama [2]. Pada penelitian yang dilakukan oleh Jaroji, Danuri, \& Putra [3] yaitu menerapkan Algoritma K-means untuk menentukan calon penerima Beasiswa Bidikmisi dari hasil clustering mahasiswa yang sangat layak, layak, dipertimbangkan dan kurang layak untuk menerima beasiswa ini dipertimbangakan 4 syarat yaitu keadaan rumah, jumlah tangunggan, prestasi di bidang akademik, penghasilan orang tua.

Penelitian yang dilakukan oleh Rismawan \& Kusumadewi [4] yaitu menerapkan Algoritma k-means untuk menggelompokkan data berdasarkan status gizi dan ukuran tubuhnya dengan mengunakan parameter bentuk badannya sendiri, sehingga seseorang tersebut bisa mengontrol berat badan supaya terus dalam keaadan yang ideal [5]. Penelitian menggunakan Algoritma K-means juga digunakan untuk mengkasterisasi data pengusulan beasiswa Bantuan Belajar Mahasiswa (BBM) yang dibagi menjadi 3 centroid yaitu berhak 
menerima, dengan pertimbangan, dan tidak berhak menerima beasiswa bidikmisi [6]. Tujuan dari penelitian ini menggunakan algoritma K-means untuk membantu menghitung nilai kemurniannya dari hasil clustering yang dilakukan. Tujuan dari penelutian ini dilakukan untuk membantu klasterisasi pengusulan mahasiswa yang layak dan tidak layak untuk menerima beasiswa dengan 4 syarat yaitu penghasilan orang tua, keadaan rumah, jumlah tanggungan, dan prestasi mahasiswa di bidang akademik. Dan untuk mempermudah melihat hasil nilai kemurniannya dari hasil clustering tersebut.

\section{METODE}

Pengelompokkan data mahasiswa menggunakan Algoritma K-Means, terdiri dari indeks prestasi kumulatif (IPK) mahasiswa, pendapatan orang tua, jumlah kehadiran, dan jarak tempuh mahasiswa. Penelitian ini menggunakan data buatan mahasiswa. Algoritma K-Means merupakan algoritma yang mengelompokkam data ke dalam cluster - cluster sehingga data yang memiliki karakter yang sama berada pada cluster yang sama dan data yang memiliki ketidaksamaan berada pada cluster yang lain [7], cara pengelompokkan menggunakan k-mean yaitu :

1. Menentukan banyaknya cluster yang dibentuk ada 4 cluster $(\mathrm{k}=4)$. Penentuan cluster harus lebih kecil dari pada banyaknya data $(\mathrm{k}<\mathrm{n})$.

2. Menentukan nilai secara manual atau random untuk pusat cluster awal sebanyak cluster yang ditentukan.

3. Untuk menghitung jarak data dengan centroid menggunakan rumus Euclidiean Distance. Persamaan 1 Euclidian Distance. [8]

$$
d(x, y)=\sqrt{\sum_{i=1}^{n}\left(x_{i}-y_{i}\right)^{2}}
$$

4. Mengecek setiap data berdasarkan kedekatannya dengan jarak terkecil [9].

5. Centroid baru dihitung dengan menghitung nilai rata-rata data pada setiap cluster.

6. Melakukan perulangan. Jika perhitugan iterasi baru berbeda dengan iterasi sebelumnya, maka proses dilanjutkan ke langkah perulangan selanjutnya. Namun jika iterasi yang baru dihitung sama dengan iterasi sebelumnya, maka proses clustering selesai. Maka nilai pusat cluster $(\mu \mathrm{j})$ pada iterasi terakhir akan digunakan sebagai parameter untuk menentukan klasifikasi data [10].

\section{PEMBAHASAN}

Pengumpulan data pengujian yang digunakan berupa data calon beasiswa bidikmisi yang menggunakan data sintetik dengan komponen penyusun data sebagai adalah mempunyai 6 atribut yaitu nis, nama, IPK , jarak tempuh, kehadiran mahasiswa, dan pendapatan orang tua. Jumlah instance adalah 25. Perhitungan clustering mengikuti langkah-langkah berikut:

1. Menentukan mahasiswa yang mendapatkan beasiswa. Jumlah kelompok ditetapkan berdasarkan pengusulan hasil seleksi beasiswa bidikmisi yaitu IPK mahasiwa, jarak tempuh mahasiswa, jumlah kehadiran, dan pendapatan orang tua. Oleh karena itu jumlah kelompok yang ditetapkan adalah 4 kelompok.

2. Inisialisasi pusat cluster (centroid) secara random. 


\begin{tabular}{|c|c|c|c|c|c|}
\hline NIS & NAMA & $\begin{array}{c}\text { Ipk } \\
\text { Mahasiswa }\end{array}$ & Jarak Tempuh & Jumlah & Pendapatan \\
\hline & & & $\begin{array}{l}\text { Mahasiswa } \\
(\mathbf{K m})\end{array}$ & Kehadiran & Orang Tua $(\mathbf{J t})$ \\
\hline 1755201001 & Binti Masruroh & 2.98 & 2 & 90 & 3 \\
\hline 1755201002 & Biyada Cyntia Irjayani & 3.53 & 8 & 86 & 2 \\
\hline 1755201003 & Faizin Choirul Umam & 3.03 & 7 & 79 & 1 \\
\hline 1755201004 & Heru Setiawan & 3.18 & 6 & 84 & 2 \\
\hline 1755201005 & Ilham Kurniawan & 2.73 & 7 & 77 & 1 \\
\hline 1755201006 & Indro Cahyo Wibowo & 2.9 & 8 & 85 & 2 \\
\hline 1755201007 & Kharisma Sabbihatul & 2.9 & 2 & 83 & 2 \\
\hline 1755201008 & Masyukur & 2.95 & 9 & 76 & 2 \\
\hline 1755201009 & Nanik Yustia Ningsih & 3.38 & 1 & 82 & 2 \\
\hline 1755201010 & Agustin Ely Rahayu & 3.48 & 12 & 92 & 1 \\
\hline 1755201011 & Moh. Arif Rofiqi & 3.63 & 15 & 83 & 1 \\
\hline 1755201012 & $\begin{array}{l}\text { Muhammad Alwi } \\
\text { Zamzami }\end{array}$ & 3.33 & 15 & 82 & 3 \\
\hline 1755201013 & Nashihatus Sholihah & 3.08 & 15 & 85 & 2 \\
\hline 1755201014 & Riska Fitri Alifah & 3.16 & 16 & 89 & 3 \\
\hline 1755201015 & Ulfa Suzana Inda & 2.95 & 13 & 88 & 2 \\
\hline 1755201016 & Egy Nadya & 2.9 & 4 & 78 & 1 \\
\hline 1755201017 & Imam Baihaqi & 3.38 & 4 & 76 & 1 \\
\hline 1755201018 & Winda Puji Larasati & 2.83 & 4 & 73 & 3 \\
\hline 1755201019 & Naela Nur Choiriyiah & 3.73 & 8 & 88 & 2 \\
\hline 1755201020 & Gunawan & 3.18 & 2 & 88 & 1 \\
\hline 1755201021 & Fiqih Ainul Qabib & 3.48 & 2 & 88 & 1 \\
\hline 1755201022 & Dhinar Syarifudin & 3 & 4 & 85 & 2 \\
\hline 1755201023 & Mujarotin Pratiwi & 3.83 & 7 & 91 & 3 \\
\hline 1755201024 & Ilham Al Ma'arif & 3.48 & 6 & 92 & 2 \\
\hline 1755201025 & Mistina Dia Rohmah & 3.23 & 7 & 91 & 2 \\
\hline
\end{tabular}

Pada Tabel 1 menunjukkan jumlah kelompok ditetapkan berdasarkan pengusulam hasil seleksi beasiswa bidikmisi yaitu IPK mahasiwa, jarak tempuh mahasiswa, jumlah kehadiran, dan pendapatan orang tua. Yang nantinya jumlah kelompok yang ditetapkan adalah 4 kelompok.

\section{Penentuan pusat awal cluster}

Tabel 2. Tabel Iterasi 1

\begin{tabular}{|l|r|r|r|r|}
\hline TENTUKANLAH JUMLAH CLUSTER DATA \\
\hline 1. PENENTUAN PUSAT AWAL CLUSTER \\
\hline Egy Nadya & 2,9 & 4 & 78 & 1 \\
\hline Nanik Yustia Ningsih & 3,38 & 1 & 82 & 2 \\
\hline Moh. Arif Rofiqi & 3,63 & 15 & 83 & 1 \\
\hline Mujarotin Pratiwi & 3,83 & 7 & 91 & 3 \\
\hline
\end{tabular}

\section{Menentukan titik pusat clustering}

Tabel.3 Tabel Perhitungan Jarak Pusat Clustering

\begin{tabular}{|c|l|c|c|c|c|c|c|c|c|c|}
\hline NIS & NAMA & IPK & Jarak tempuh & Jumlah & Pendapatan & C1 & C2 & C3 & C4 & CLUSTER \\
\hline & & & Mahasiswa $(\mathrm{km})$ & Kehadiran & Orang tua $(\mathrm{jt})$ & & & & & \\
\hline 1755201001 & Binti Masruroh & 2.98 & 2 & 90 & 3 & 12.33 & 8.13 & 14.91 & 5.17 & 4 \\
\hline 1755201002 & Biyada Cyntia I & 3.53 & 8 & 86 & 2 & 9.02 & 8.06 & 7.68 & 5.20 & 4 \\
\hline 1755201003 & Faizin Choirul & 3.03 & 7 & 79 & 1 & 3.16 & 6.79 & 8.96 & 12.19 & 1 \\
\hline 1755201004 & Heru Setiawan & 3.18 & 6 & 84 & 2 & 6.41 & 5.39 & 9.12 & 7.17 & 2 \\
\hline 1755201005 & Ilham K & 2.73 & 7 & 77 & 1 & 3.17 & 7.90 & 10.04 & 14.18 & 1 \\
\hline
\end{tabular}




\begin{tabular}{|l|l|l|l|l|l|l|l|l|l|l|}
\hline 1755201006 & Indro Cahyo W & 2.9 & 8 & 85 & 2 & 8.12 & 7.63 & 7.38 & 6.23 & 4 \\
\hline 1755201007 & Kharisma S & 2.9 & 2 & 83 & 2 & 5.48 & 1.49 & 13.06 & 9.53 & 2 \\
\hline 1755201008 & Masyukur & 2.95 & 9 & 76 & 2 & 5.48 & 10.01 & 9.30 & 15.19 & 1 \\
\hline 1755201009 & Nanik Yustia N & 3.38 & 1 & 82 & 2 & 5.12 & 0.00 & 14.07 & 10.87 & 2 \\
\hline 1755201010 & Agustin Ely R & 3.48 & 12 & 92 & 1 & 16.13 & 14.90 & 9.49 & 5.49 & 4 \\
\hline 1755201011 & Moh. Arif R & 3.63 & 15 & 83 & 1 & 12.11 & 14.07 & 0.00 & 11.49 & 3 \\
\hline 1755201012 & Muhammad A & 3.33 & 15 & 82 & 3 & 11.88 & 14.04 & 2.26 & 12.05 & 3 \\
\hline 1755201013 & Nashihatus S & 3.08 & 15 & 85 & 2 & 13.08 & 14.32 & 2.30 & 10.08 & 3 \\
\hline 1755201014 & Riska Fitri A & 3.16 & 16 & 89 & 3 & 16.40 & 16.58 & 6.42 & 9.24 & 3 \\
\hline 1755201015 & Ulfa Suzana I & 2.95 & 13 & 88 & 2 & 13.49 & 13.42 & 5.52 & 6.84 & 3 \\
\hline 1755201016 & Egy Nadya & 2.9 & 4 & 78 & 1 & 0.00 & 5.12 & 12.11 & 13.52 & 1 \\
\hline 1755201017 & Imam Baihaqi & 3.38 & 4 & 76 & 1 & 2.06 & 6.78 & 13.04 & 15.43 & 1 \\
\hline 1755201018 & Winda Puji & 2.83 & 4 & 73 & 3 & 5.39 & 9.56 & 15.02 & 18.28 & 1 \\
\hline 1755201019 & Naela Nur & 3.73 & 8 & 88 & 2 & 10.85 & 9.23 & 8.66 & 3.32 & 4 \\
\hline 1755201020 & Gunawan & 3.18 & 2 & 88 & 1 & 10.20 & 6.17 & 13.94 & 6.20 & 2 \\
\hline 1755201021 & Fiqih Ainul & 3.48 & 2 & 88 & 1 & 10.21 & 6.17 & 13.93 & 6.17 & 2 \\
\hline 1755201022 & Dhinar S & 3 & 4 & 85 & 2 & 7.07 & 4.26 & 11.24 & 6.83 & 2 \\
\hline 1755201023 & Mujarotin P & 3.83 & 7 & 91 & 3 & 13.52 & 10.87 & 11.49 & 0.00 & \multicolumn{2}{|c|}{4} \\
\hline 1755201024 & Ilham Al Ma'arif & 3.48 & 6 & 92 & 2 & 14.19 & 11.18 & 12.77 & 1.77 & 4 \\
\hline
\end{tabular}

Tabel 2 menunjukkan penentuan pusat awal cluster. Disini kita membagi menjadi 4 cluster. Pada Tabel 3, Perhitungan jarak pusat cluster, yang mana pada cluster yang paling tinggi nilainya yiutu cluster yang dipilih. Tabel 4 menjelaskan dalam perhitungan $\mathrm{c} 1$ berjumlah 6 dengan melihat data dari perhitungan jarak pusat cluster c1. Dalam perhitungan c2 berjumlah 6 dengan melihat data dari perhitungan jarak pusat cluster c2. Dalam perhitungan c3 berjumlah 9 dengan melihat data dari perhitungan jarak pusat cluster c3. Dalam perhitungan c4 berjumlah 4 dengan melihat data dari perhitungan jarak pusat cluster $\mathrm{c} 4$. Tabel 5 menjelaskan tetang hasil iterasi yang kedua yang menentukan hasil cluster dan berhenti di iterasi ke 2 karena perhitungan jarak pusat sudah tidak berubah.

Tabel 4. Perhitungan Jarak Pusat Cluster

\begin{tabular}{|l|l|l|l|l|}
\hline \multicolumn{1}{|c|}{ C1 } & \multicolumn{1}{c|}{ C2 } & \multicolumn{1}{c|}{ C3 } & \multicolumn{1}{c|}{ C4 } \\
\hline C1 BERJUMLAH 6 & 02,97 & 03 & 03,23 & 03 \\
\hline C2 BERJMLAH 6 & 05,83 & 03 & 014,8 & 07 \\
\hline C3 BERUMLAH 9 & 076,50 & 085 & 085,40 & 089 \\
\hline C4 BERJUMLAH 4 & 01,5 & 02 & 02,20 & 02 \\
\hline
\end{tabular}

Tabel 5. Tabel Iterasi 2

\begin{tabular}{|c|c|c|c|c|}
\hline \multirow[b]{3}{*}{ ITERASI KE-2 } & \multicolumn{4}{|c|}{ 1. PENENTUAN PUSAT AWAL CLUSTER } \\
\hline & \multicolumn{4}{|c|}{ HASIL DARI PENGELOMPOKAN DATA 1 DIBAGI JUMLAH TOTAL Cn } \\
\hline & $\mathrm{C} 1$ & $\mathrm{C} 2$ & C3 & \begin{tabular}{|l}
$\mathrm{C} 4$ \\
\end{tabular} \\
\hline CLUSTER BARU YANG KE 1 & 2,97 & 5,83 & 76,50 & 2 \\
\hline CLUSTER BARU YANG KE 2 & 3,19 & 2,83 & 85,00 & 2 \\
\hline CLUSTER BARU YANG KE 3 & 3,23 & 14,80 & 85,40 & 2 \\
\hline CLUSTER BARU YANG KE 4 & 3,40 & 7,25 & 89,38 & 2 \\
\hline
\end{tabular}

\section{KESIMPULAN}

Hasil dari penelitian yang telah dilakukan, Algoritma K-Means bisa membantu mengklasterisasi calon penerima beasiswa dalam 4 cluester yaitu sangat layak, kurang layak, dipertimbangkan, dan tidak layak menerima beasiswa bidikmisi. Hasil klasterisasi hanya merupakan pengusulan untuk mengambil keputusan dan bukan sebagai keputusan akhir penerima beasiswa bidikmisi mahasiswa. 


\section{REFERENSI}

[1] J. Jaroji, D. Danuri, and F. P. Putra, "K-MEANS UNTUK MENENTUKAN CALON PENERIMA BEASISWA BIDIK MISI DI POLBENG," INOVTEK Polbeng - Seri Inform., 2016.

[2] R. Fauzan, Y. Indrasary, and N. Muthia, "Sistem Pendukung Keputusan Penerimaan Beasiswa Bidik Misi di POLIBAN dengan Metode SAW Berbasis Web,” J. Online Inform., 2018.

[3] A. Bastian et al., "Penerapan Algoritma," Jsi.Cs.Ui.Ac.Id, 2009.

[4] T. Rismawan and D. S. Kusumadewi, "Aplikasi K-Means Untuk Pengelompokkan Mahasiswa Berdasarkan Nilai Body Mass Index (Bmi) \& Ukuran Kerangka,” Semin. Nas. Apl. Teknol. Inf., 2008.

[5] T. Rismawan, “Aplikasi K-Means Untuk Pengelompokkan Mahasiswa,” Apilkasi K-Means Untuk Pengelompokan Mhs. Berdasarkan Nilai Body Mass Ukuran Kerangka, 2008.

[6] mohamad jajuli nurul rohmawati, sofi defiyanti, "Implementasi Algoritma K-Means Dalam Pengklasteran Mahasiswa Pelamar Beasiswa," Jitter 2015, 2015.

[7] A. E. Wicaksono, "Implementasi Data Mining Dalam Pengelompokan Peserta Didik di Sekolah untuk Memprediksi Calon Penerima Beasiswa Dengan Menggunakan Algoritma K-Means (Studi Kasus SMA N 6 Bekasi)," Jur. Tek. Inform. Univ. Gunadarma, 2016.

[8] Ediyanto, M. N. Mara, and N. Satyahadewi, "Pengklasifikasian Karakteristik Dengan Metod KMeans Cluster Analysis," Bul. Ilm., 2013.

[9] N. Fitria Hastuti, "Pemanfaatan metode k-means clustering dalam penentuan penerima beasiswa," Skripsi, 2013.

[10] A. Sani, "Penerapan Metode K-Means Clustering Pada Perusahaan,” J. Ilm. Teknol. Inf., 2018. 